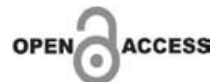

Correspondence addresses:

Dra. Viviane B. Ferreira

flaca@uol.com.br

Received: September 26, 2019

Revised: October 26, 2019

Accepted: October 30, 2019

Published: December 2 ${ }^{\text {nd }}, 2019$

Data Availability Statement: All relevant data are within the paper and its Supporting Information files.

Funding: This work was the result of authors' initiative. There was no support of research or publication funds.

Competing interests: The authors have declared that no competing interests exist.

Copyright

(C) 2019 by Santa Casa

de Misericórdia da Bahia.

All rights reserved.

ISSN: 2526-5563
RELATO DE CASO

\section{Síndrome de Guillain-Barré (SGB) em Paciente com Encefalite Viral e Sorologias Positivas para Herpes e Dengue}

\author{
Guillain-BarréSyndrome (GBS) in a Patientwith ViralEncephalitis \\ and Positive for Herpes and Dengue
}

Viviane Borges Ferreira', Fernanda Cristina Rodrigues Douborg', Ramon Campos
Nascimento ${ }^{1}$, Érica Rosário Costa Pinto Silva ${ }^{1}$

Dengue é a infecção arboviral humana mais frequente, com aproximadamente 80 milhões de casos registrados por ano e 2,5 a 3 bilhões de indivíduos sob risco de acordo com estimativas da Organização Mundial de Saúde. Seu sintoma depende da forma clínica, podendo variar de cefaleia a ampla gama de manifestações neurológicas. A incidência anual de encefalite é de 5 a 10 casos/100.000 habitantes, predominantemente em jovens e idosos. A encefalite por herpes simplex vírus (HSV) é a encefalite mais diagnosticada nos países industrializados, com uma incidência anual de 1 caso/250.000 ou 500.000 mil habitantes. A maioria dos casos de encefalite por HSV é devida ao HSV-1 e cerca de $10 \%$ por HSV-2. Este último ocorre tipicamente em indivíduos imunodeprimidos e neonatos em quem surge infecção disseminada. Este trabalho relata o caso de uma jovem de 14 anos que apresentou febre, dor abdominal, vômitos e cafeleia. Evoluiu com exantema fugaz. Três dias após a alta, apresentou piora da cefaleia, recusa alimentar, tontura, artralgia e tetraparesia completa. O diagnóstico da Síndrome de Guillain-Barré foi baseado nos achados clínicos e no exame de ressonância magnética (RNM) de coluna, posteriormente confirmados pelos achados eletrofisiológicos. $\mathrm{E}$ as infecções por herpes e dengue foram confirmadas pelos títulos específicos de IgM no sangue.

Palavras-chave: Síndrome de Guillain-Barré; Herpes; Dengue; Encefalite.

Dengue is the most common human arboviral infection with approximately 80 million cases reported per year, and 2.5 to 3 billion individuals at risk according to World Health Organization. The symptoms depend on the clinical form and may vary from headache to neurological manifestations. The annual incidence of encephalitis is 5 to 10 cases $/ 100,000$ inhabitants, predominantly in young and old people. Herpes simplex virus (HSV) encephalitis is the most commonly diagnosed encephalitis in development countries, with an annual incidence of 1 case $/ 250,000$ or 500,000 inhabitants. Most cases of HSV encephalitis are due to HSV-1 and about $10 \%$ due to HSV-2. The HSV-2 typically occurs in immunosuppressed individuals and neonates. We repot a case of a 14 year-old-girl who presented fever, abdominal pain, vomiting and headache, evolving to cutaneous rash. Three days after discharge, the patient presented worsening headache, refusal to eat, dizziness, arthralgia and complete tetraparesis. The diagnosis of GuillainBarré Syndrome was based on clinical findings and spinal magnetic resonance imaging (MRI), confirmed by electrophysiological findings. Herpes and dengue infections were confirmed by specific IgM titers in the blood.

Keywords: Guillain-Barré Syndrome; Herpes; Dengue; Encefalitis. 


\section{Introdução}

Paciente do sexo feminino, 14 anos, foi internada com queixas de febre, dor abdominal, vômitos e cafeleia. Evoluiu com exantema fugaz. Recebeu alta com o diagnóstico presuntivo de dengue. Três dias após a alta, apresentou piora da cefaleia, recusa alimentar, tontura e artralgia. A cefaleia era resistente à analgesia e foi necessário o uso de morfina. Foi novamente internada. Realizou tomografia computadorizada (TC) e ressonância nuclear magnética (RNM) de crânio e foi colhido líquor céfalorraquidiano (LCR), que foram normais. A paciente queixavase de dor e fraqueza generalizadas. A paciente tinha antecedentes de distúrbios emocionais, deflagrados após a separação dos pais.

Diante da intensidade dos sintomas, não responsivos à analgesia e com os exames de imagem e infecciosos normais, cogitou-se a possibilidade de Transtorno Somatoforme. Foi solicitada avaliação psiquiátrica. O psiquiatra constatou que a paciente apresentava sintomas ansiosos, com preocupação excessiva com questões do cotidiano, irritabilidade e baixo limiar de frustração.

Familiares referiam que a paciente passou a brigar com colegas, a tornar-se mais beligerante e rebelde, com perda do rendimento escolar. Cerca de 8 meses da internação, a mãe da paciente foi morar em São Paulo e desde então a paciente não a viu mais pessoalmente, apenas por videochamadas. Tias referiam que a paciente passou a se tornar reclusa e isolada. Paciente e tias referiram mudanças muito intensas no humor e no comportamento, a ponto da paciente isolar-se completamente de amigos e familiares. Paciente referia que desde a separação dos pais: "já não é mais feliz como antes".

Por ocasião da avaliação psiquiátrica, a paciente já estava se queixando de fraqueza nos membros, porém, diante do contexto, tanto os familiares como a equipe que a assistia, atribuíam suas queixas à necessidade de requisitar a presença dos pais.

As hipóteses diagnósticas psiquiátricas foram:
1. Transtorno dissociativo/conversivo.

2. Transtorno Depressivo com sintomas ansiosos? Ansiedade generalizada com alterações do humor?

Iniciado tratamento com sertralina e indicado apoio da psicologia.

Como Transtorno Conversivoéum diagnóstico de exclusão, a paciente continuou sendo avaliada e acompanhada pela equipe da pediatria.

Realizado exame neurológico, constatou-se a tetraparesia referida pela paciente. A avaliação da força muscular depende da colaboração do paciente, podendo haver simulação.

Contudo, a paciente apresentava fraqueza facial, com dificuldade para o fechamento dos olhos e, na pesquisa dos reflexos profundos, apresentava arreflexia. Esses achados são totalmente independentes da ação voluntária da paciente. A paciente apresentava fala disártrica, provavelmente provocada pela fraqueza dos músculos da face.

Diante do quadro clínico, a despeito da ausência de dissociação proteíno-citológica no LCR, foi aventada a hipótese diagnóstica de Síndrome de Guillain-Barré e indicado o tratamento com imunoglobulina, sob monitorização em unidade de terapia intensiva (UTI).

Para confirmar o diagnóstico, foi solicitada RNM de coluna vertebral, a fim de pesquisar se havia a presença de realce anormal nas raízes nervosas. A RNM de coluna lombo-sabra mostrou realce difuso e simétrico das raízes da cauda equina, confirmando o diagnóstico de Síndrome de Guillain-Barré (Figuras 1 e 2).

A paciente evoluiu com disautonomia, com hipertensão arterial sistêmica (HAS) resistente a anti-hipertensivosecominsuficiênciarespiratória, necessitando de ventilação mecânica.

Como havia história sugestiva de infecção viral, foram solicitadas sorologias para herpes e arboviroses. As sorologias para herpes e dengue mostraram IgG e IgM reagentes.

A paciente recebeu $2 \mathrm{~g} / \mathrm{Kg}$ de imunoglobulina por 5 dias e 14 dias de aciclovir. Evoluiu com melhora paulatina, sendo extubada, recebendo 
Figura 1A e 1B. RNM de coluna lombar apresentando realce anormal das raízes da cauda equina.

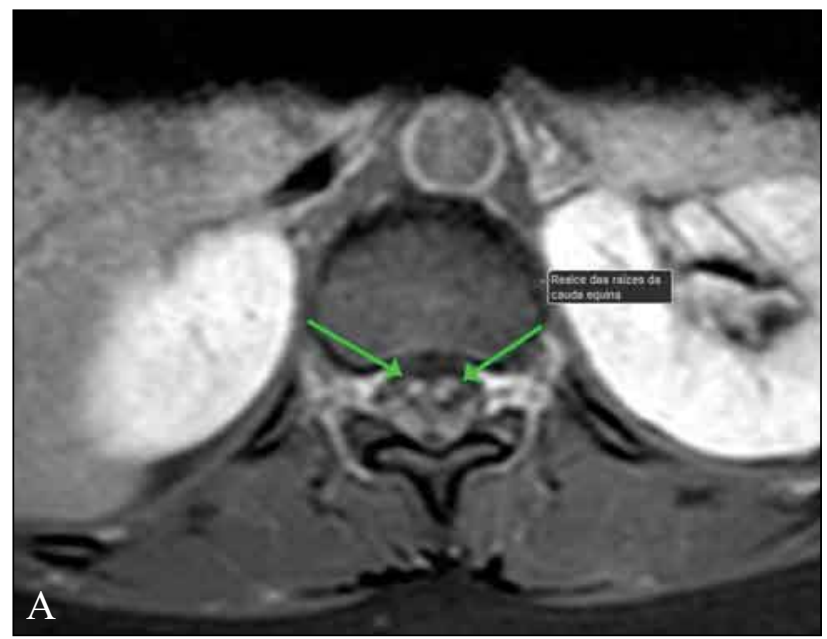

alta para enfermaria e posteriormente alta para o domicílio, deambulando com marcha parética, assimétrica, pior em hemicorpo direito $\mathrm{e}$ mantendo a paresia facial, pior à esquerda.

Após a imunoglobulina, foi introduzida prednisona $60 \mathrm{mg} / \mathrm{dia}$, com orientação para redução semanal.

Realizou eletroneuromiografia dos quatro membros edaface, jáno períododeconvalescença, que mostrou polineuropatia sensitivo-motora, do tipo axonal e mielínico, de predomínio mielínico,

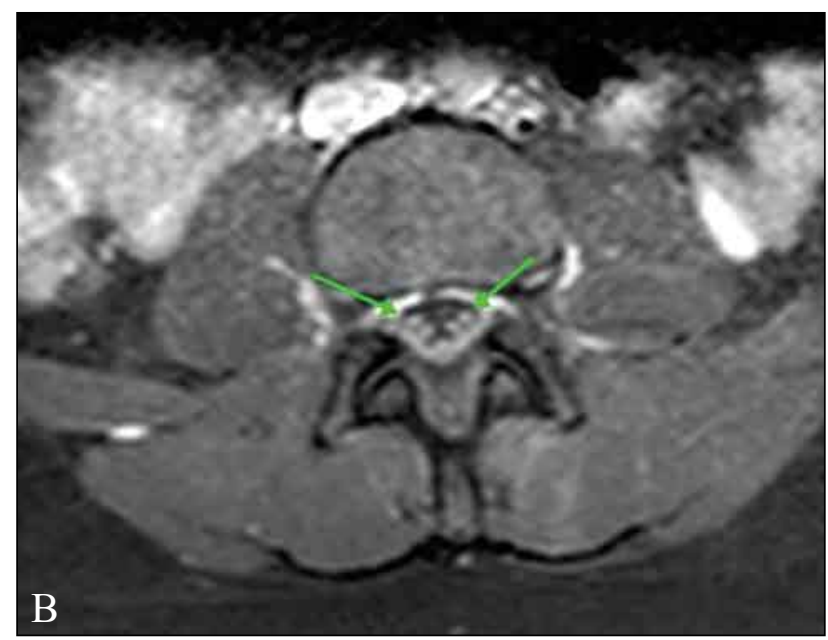

sugestiva de polineuropatia desmielinizante inflamatória, subaguda, com sinais de reinervação à miografia (Figuras 3 e 4).

Atualmente, está no domicílio, em esquema de retirada do corticoide, em tratamento fisioterápico intensivo, além de acompanhamento psiquiátrico e psicológico.

Confirmada as hipóteses de Síndrome de Guillain-Barré e diagnósticos sorológicos de infecções pelos vírus da herpes e da dengue, com presença de IgM positivos para os dois tipos de vírus.

Figura 2. Latências das ondas "F" (resposta motora tardia), aumentadas. Achado comum na neurocondução na SGB, que indica comprometimento motor proximal.
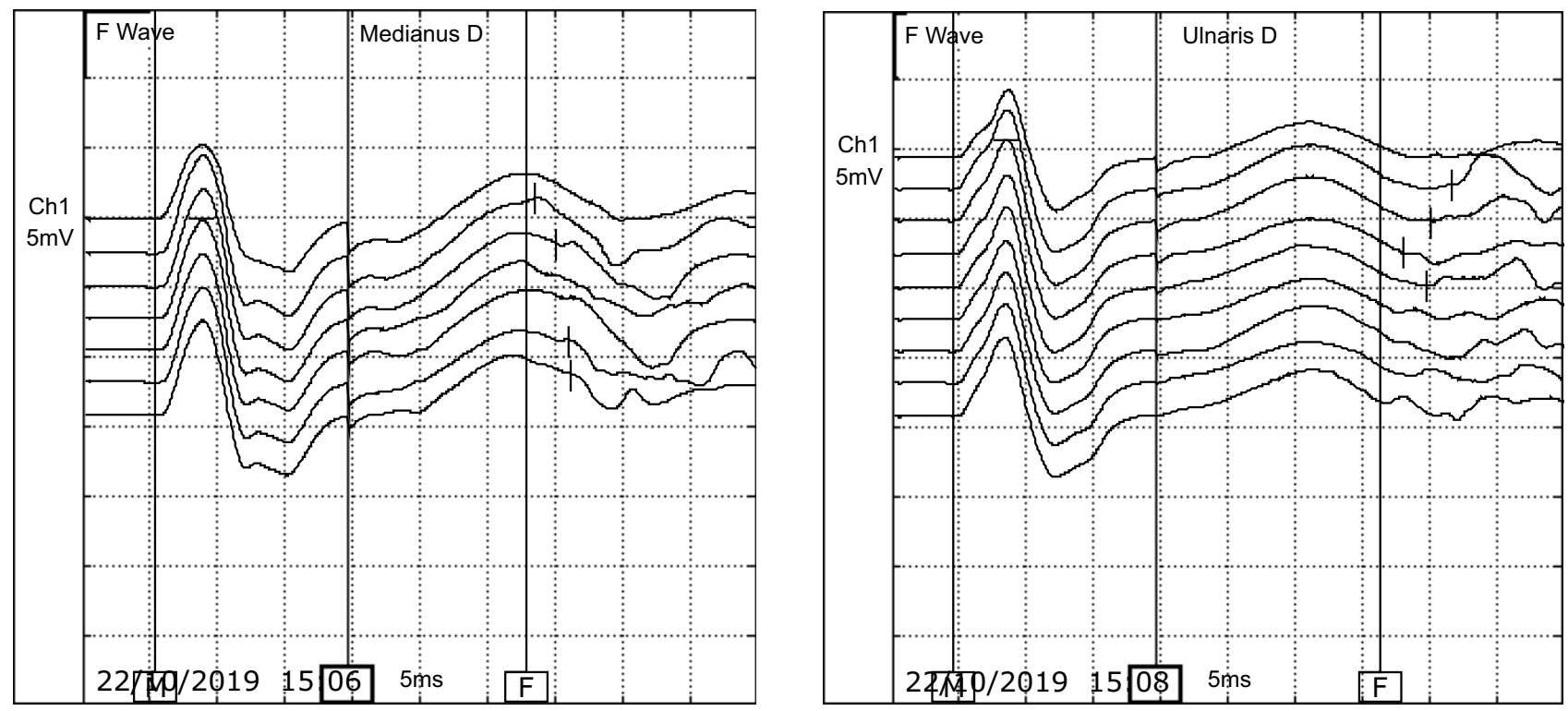
Figura 3. Potencial de ação motor complexo do ramo mandibular do nervo facial direito, mostrando dispersão temporal, achado típico de comprometimento mielínico.

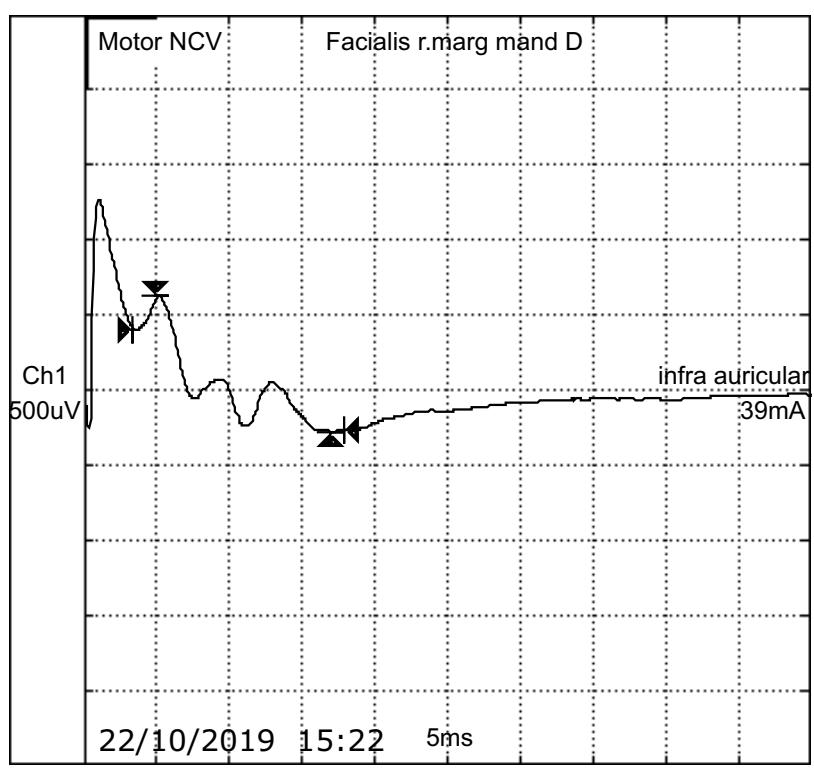

\section{Discussão}

A Síndrome de Guillain-Barré (SGB) pode ser descrita como uma coleção de síndromes clínicas que se manifesta como uma polirradiculoneuropatia inflamatória aguda com fraqueza resultante e reflexos diminuídos.

Embora a descrição clássica do SGB seja a de uma neuropatia desmielinizante com fraqueza crescente, muitas variantes clínicas foram bem documentadas na literatura médica. ${ }^{1}$

A incidência anual é de 1-4 casos por 100.000 habitantes e pico entre 20 e 40 anos de idade.

\section{$\underline{\text { Sinais e Sintomas }}$}

O paciente típico com SGB, que na maioria dos casos se manifestará como polirradiculoneuropatia desmielinizante inflamatória aguda (AIDP), apresenta 2-4 semanas após uma doença respiratória ou gastrointestinal relativamente benigna com queixas de disestesia dos dedos e fraqueza muscular proximal das extremidades inferiores. A fraqueza pode progredir de horas a dias para envolver os braços, músculos do tronco, nervos cranianos e músculos da respiração.
Asqueixascomunsassociadasaoenvolvimento dos nervos cranianos na SGB incluem: paresia facial (pode imitar a paralisia de Bell), diplopias, disartria, disfagia, oftalmoplegia e alterações pupilares.

A maioria dos pacientes se queixa de parestesias, dormência ou alterações sensoriais semelhantes. As parestesias geralmente começam nos dedos dos pés e nas pontas dos dedos, progredindo para cima, mas geralmente não se estendendo além dos pulsos ou tornozelos.

A dor associada à SGB é mais intensa na cintura escapular, costas, nádegas e coxas e pode ocorrer mesmo com os menores movimentos.

Alterações autonômicas na SGB costumam provocar: taquicardia, bradicardia, rubor facial, hipertensão paroxística, hipotensão ortostática, anidrose e / ou diaforese e retenção urinária.

Pode evoluir com comprometimento respiratório, de leve à insuficiência respiratória.

\section{Diagnóstico}

O diagnosticado da SGB é clínico. Os exames subsidiários mais utilizados são:

1. Líquor céfalorraquidiano: costuma mostrar dissociação proteíno-citológica (discreta pleocitose, com hiperproteínorraquia superior a $40 \mathrm{mg} \%$ ).

2. Estudos de eletroneuromiografia: o estudo da neurocondução costuma mostrar sinais de desmielinização: redução da velocidade da condução nervosa, prolongamento das latências distais, prolongamento das ondas " $\mathrm{F}$ ", bloqueio de condução ou dispersão de respostas: Evidências frequentemente demonstradas em locais de compressão nervosa. A miografia com eletrodos de agulhas costuma mostrarpadrão de recrutamento rarefeito.

3. Ressonância nuclear magnética (RNM) de coluna vertebral pode ajudar a excluir lesões na medula espinhal devido a compressão (por exemplo, por um tumor ou um abscesso) e mielite transversa (inflamação da medula espinhal). Realce anômalo das raízes nervosas é sugestivo de polirradiculineurite. 


\section{Tratamento}

Os pacientes diagnosticados com SGB devem ser internados em um hospital para monitoramento rigoroso até que seja determinado que o curso da doença atingiu um platô ou sofreu reversão. Embora a fraqueza possa inicialmente ser leve e não incapacitante, os sintomas podem progredir rapidamente em apenas alguns dias. A progressão contínua pode resultar em uma emergência neuromuscular com paralisia profunda, insuficiência respiratória e/ ou disfunção autonômica com complicações cardiovasculares.

Aproximadamente um terço dos pacientes requerem admissão em uma UTI, principalmente por causa de insuficiência respiratória. Após a estabilização médica, os pacientes podem ser tratados em um andar médico/ neurológico geral, mas a vigilância contínua continua sendo importante na prevenção de complicações respiratórias, cardiovasculares e outras complicações médicas. Pacientes com comprometimento funcional persistente podem precisar ser transferidos para uma unidade de reabilitação hospitalar.

Também é necessário cuidado continuado para minimizar os problemas relacionados à imobilidade, intestino e bexiga neurogênicos e dor. Recomenda-se o envolvimento precoce da equipe multidisciplinar.

$\mathrm{O}$ reconhecimento e o tratamento precoces da SGB também podem ser importantes no prognóstico a longo prazo, especialmente no paciente com maus sinais prognósticos clínicos, como idade avançada, curso em rápido progresso e diarreia antecedente.

O tratamento imunomodulador tem sido usado para acelerar a recuperação. A imunoglobulina intravenosa (IGIV) ou a plasmaferese mostraramse igualmente eficazes.

Em tese, qualquer infecção pode desencadear o processo autoimune que desencadeia a SGB e, na maioria das vezes, não é possível estabelecer com certeza o agente etiológico da infecção deflagradora.
As infecções mais comuns são as infecções intestinais. $\mathrm{O}$ agente infeccioso mais comumente associado à SGB é o Campylobcter jejunii.

Outras infecções podem desencadear essa doença: zika, dengue, chikungunya, citomegalovírus, Epstein-Barr vírus, vírus do sarampo, vírus da influenza A, Mycoplasma pneumoniae, enterovirus D68, hepatite A, B, C, HIV, dentre outros.

Durante a epidemia do zika vírus de 2016, houve um aumento extraordinário na incidência de SGB, com várias formas diferentes, além da clássica.

Apaciente apresentou quadro clínico sugestivo de Arboviroses (infecções por vírus da dengue, zika ou chicungunya). Essas arboviroses podem ter as seguintes características:

Dengue: doença febril aguda, que pode apresentar um amplo espectro clínico, pois a maioria dos pacientes se recupera após evolução clínica leve e autolimitada, enquanto uma pequena parte evolui para gravidade. É a mais importante arbovirose que afeta o homem, constituindo-se em sério problema de saúde pública no mundo; ocorre e é disseminada especialmente nos países tropicais e subtropicais, onde as condições do meio ambiente favorecem o desenvolvimento e a proliferação do Aedes aegypti e do Aedes albopictus.

Febre de Chikungunya: doença produzida pelo vírus chikungunya (CHIKV), transmitida por mosquitos do gênero Aedes, que cursa com enfermidade febril aguda, subaguda ou crônica. A enfermidade aguda se caracteriza, principalmente, por início súbito de febre alta, cefaleia, mialgias e dor articular intensa, afetando todos os grupos etários e ambos os sexos. Em uma pequena porcentagem dos casos a artralgia se torna crônica, podendo persistir por anos. As formas graves e atípicas são raras, mas quando ocorrem podem, excepcionalmente, evoluir para óbito. A febre de chikungunya é uma enfermidade endêmica nos países do Sudeste da Ásia, África 
e Oceania. Emergiu na região das Américas no final de 2013. O nome chikungunya deriva de uma palavra do idioma makonde, falado no sudeste da Tanzânia, que significa "curvar-se ou tornarse contorcido", descrevendo a postura adotada pelos pacientes devido à artralgia intensa.

Febre pelo vírus Zika: doença que foi detectada no país no ano de 2015 , e a partir deste evento, tem-se disseminado no país cursando de forma inédita. Tendo encontrado ambiente favorável à sua disseminação, que é a presença do vetor Aedes em todo o país, em população sem imunidade à doença, causou enorme impacto à saúde de nossa população. É uma doença viral aguda, transmitida principalmente, pelos mosquitos Aedes Aegypti e Aedes albopictus, caracterizada por exantema maculopapular pruriginoso, febre intermitente, hiperemia conjuntival não purulenta e sem prurido, artralgia, mialgia e dor de cabeça. Os casos costumam apresentar evolução benigna e os sintomas geralmente desaparecem espontaneamente após 3-7 dias. Todavia, observa-se a ocorrência de óbitos pelo agravo, aumento dos casos de microcefalia e de manifestações neurológicas associadas à ocorrência da doença.

A paciente apresentou sintomas sugestivos de comprometimento do sistema nervoso central (cefaleia intensa e distúrbio do comportamento) e do sistema nervoso periférico - tetraparesia flácida, arreflexia).

Sendo a Síndrome de Guillain-Barré uma doença rara, é plausível supor que a sua ocorrência e o diagnóstico clínico prévio de dengue no momento da admissão da paciente, estão causalmente associados. ${ }^{9}$ No entanto, a paciente apresentava sorologias IGM positivas para dengue e HSV, este último responsável, mesmo após a terapia antiviral, por até $20 \%$ de óbitos e sequelas neurológicas persistentes, e também descrito em associação com a Síndrome de Guillain-Barré. ${ }^{10}$

Diante desse quadro clínico, podemos inferir que a paciente foi infectada pelos vírus da dengue e/ou da herpes, que o sistema imunológico da paciente não só permitiu o acesso dos agentes infecciosos ao encéfalo, sem reação inflamatória meníngea, mas também desencadeou a reação autoimune que culminou na Síndrome de Guillain-Barré.

A hipótese diagnóstica aventada foi encefalite viral (herpética e/ou pelo vírus da dengue) que evoluiu com Síndrome de Guillain-Barré.

\section{Conclusão}

Este caso apresenta vários pontos que merecem ser salientados:

1. É possível e não é rara a ocorrência de encefalite sem meningite. $\mathrm{O}$ achado de LCR normal não descarta a hipótese de encefalite infecciosa ou inflamatória. ${ }^{3}$

2. É possível ocorrência de Síndrome de GuillainBarrésem dissociaçãoproteíno-citológica,com ou sem alteração na contagem de leucócitos, com proteinorraquia normal. Provavelmente, em algum momento da evolução, deve ter havido variação nesses parâmetros, contudo, nem sempre, no momento em que é feita a coleta do LCR, necessariamente são flagradas as alterações de leucócitos e da proteína. $\mathrm{Ou}$ seja, LCR normal, não descarta a hipótese diagnóstica de Síndrome de Guillain-Barré (na primeira semana, a proteína no líquor pode ser normal em até $1 / 3$ dos pacientes). ${ }^{4}$

3. A ressonância nuclear magnética de coluna tem-se revelado uma ferramenta útil para estabelecer o diagnóstico de SGB, principalmente nos casos em que o líquor céfalorraquidiano é normal.

4. A SGB é uma patologia cujo diagnóstico é clínico. Mesmo que os exames subsidiários não mostrem os achados esperados, a clínica é soberana e quanto mais cedo é instituído o tratamento imunomodulador, melhores são as chances de recuperação do paciente.

5. Embora a incidência de Transtornos Somatoformes não seja rara (de 5,08 a 8,06\% dos atendimentos psicológicos), ${ }^{2}$ trata-se de um diagnóstico de exclusão. Todas as 
causas orgânicas que podem provocar os sintomas referidos pelo paciente devem ser descartados. No caso em questão, a paciente poderia voluntária ou involuntariamente provocar a fraqueza muscular, contudo, a arreflexia e a paresia facial com dificuldade para fechar as pálpebras não podem ser provocadas de maneira voluntária e foram os sinais clínicos que firmaram o diagnóstico de SGB e afastaram a hipótese de Transtorno Somatoforme.

6. Os agentes infecciosos que mais comumente provocam a SGB são o Campylobacter e as enteroviroses. Durante a epidemia de zika vírus, houve um número elevado de casos notificados de SGB relacionados a essa infecção. Poucos casos de dengue ou herpes como agentes deflagradores da SGB foram descritos.

\section{Referências}

1. Andary MT, Klein, MJ. Updated. 2018; May 04.

2. Ana Paula Rezzo Pires Reinert APRP, Rêgo RML, Pires RCR; Silva VC. Psicol Pesq.2016;10(2).
3. Brito MJ, Luís C, Silva R, Gouveia C, Vieira JP. Acta Pediatr Port. 2011:42(6).

4. Vucic S, Kiernan MC, Cornblath DR. Guillain-Barré Syndrome: an update. J Clin Neurosci. 2009;16(6):73341.

5. Dourado ME, Félix RH, da Silva WK, Queiroz JW, Jeronimo SM. Clinical characteristics of GuillainBarré Syndrome in a tropical country: a Brazilian experience. Acta Neurol Scand. 2012;125(1):4753.

6. Hughes RA, Cornblath DR. Guillain-Barré Syndrome. Lancet. 2005;366(9497):1653-66.

7. Olivarius BF, Buhl M. Br Med J. 1975 Jan 25; 1(5951):192-193.

8. Orsini M, Freitas MRG, Nascimento OJM, Catharino AMS, Mello MP, et al. Guillain-Barré Syndrome after dengue infection: case report.

9. Ralapanawa et al. Guillain-Barré Syndrome following dengue fever and literature review. Bmc Res Notes. 2015;8:729. Doi 10.1186/s13104-015-1672.

10. Pires LHZ, Reis CHM. Encefalite herpética por HSV-1 - relato de caso. Revista Científica da FMC. 2016; Vol.11(1).

11. Santos NQ et al. Guillain-Barré Syndrome in the course of dengue: case report. Arq Neuropsiquiatr. 2004;62(1):144-146.

12. Keesen TSL et al. Guillain-Barré Syndrome and arboviral infection in Brazil. www.thelancet.com/ infection vol 17 july 2017. 